\title{
ENTRE LA INTIMIDAD Y LA SOCIABILIDAD: LA ALIMENTACIÓN SEGÚN FRAY ANTONIO DE GUEVARA
}

\author{
MARÍA DE LOS ÁNGELES PÉREZ SAMPER \\ Universidad de Barcelona
}

Fecha de recepción: enero 2012

Fecha de aceptación: febrero 2012

Aunque la alimentación responde a una necesidad vital que cada persona debe satisfacer individualmente, a lo largo de la historia los seres humanos la hemos convertido en un potente signo social y cultural. En lugar de comer en soledad, hombres y mujeres prefieren comúnmente comer en compañía. La alimentación abarca, por tanto, la amplia gama que va desde la mayor intimidad a la mayor publicidad. Se puede disfrutar, por ejemplo, de un dulce casi en secreto o se puede asistir a un banquete con cientos de comensales. Con el alimento se establece una relación personal, que puede ser estrictamente privada, de manera que se convierta en una experiencia íntima, pero con mucha frecuencia esa experiencia se busca compartirla con otras personas y se convierte así en una experiencia social. La mesa en todos los tiempos y en todos los lugares constituye una de las máximas expresiones de sociabilidad. ${ }^{1}$

Comer en privado y mucho más comer en público retrata a la persona. Se puede comer sin guardar las formas, o se puede comer de acuerdo con la condición y el rango social que una persona tiene o busca tener y de acuerdo con las normas de cortesía existentes en cada tiempo y en cada lugar, alcanzando así un alto grado de civilidad, de aceptación y de éxito social. El buen comportamiento en privado y en público era fundamental, como expresión de un más elevado rango de humanidad. Y ello no sólo

\footnotetext{
1. Este trabajo se ha realizado en el marco de dos proyectos del Ministerio de Ciencia e Innovación. Proyecto CICYT. Convocatoria 2008. Referencia: HAR2008-06131-C02-02: «Privacidad y sociabilidad en la vida cotidiana: Ámbito doméstico y espacio público en el Antiguo Régimen: Barcelona y la España periférica». Proyecto CICYT. Convocatoria 2011. Referencia: HAR2011-26435-C03-02: «E1 hecho cotidiano en la Monarquía Española de la Edad Moderna: Cataluña y Barcelona». Se halla relacionado con otros dos trabajos: «Humanismo y Civilidad en la mesa» (Madrid, en prensa) y «Urbanidad en la mesa en la España del siglo XVIII» (Granada, en prensa).
} 
era una cuestión personal privada, sino sobre todo una manera de construir una sociedad más humana.

En toda Europa se produjo en el Renacimiento una gran preocupación por la alimentación y las buenas maneras en la mesa. ${ }^{2}$ En España uno de los autores que se ocupó del tema fue Fray Antonio de Guevara, cortesano, eclesiástico y escritor, uno de los autores más populares del Renacimiento español, pues sus obras se editaron durante los siglos XVI y XVII más de 600 veces en España y por toda Europa. En varias de sus obras hizo referencias muy interesantes a la civilidad de la alimentación y de la mesa. ${ }^{3}$

Nacido en Treceño, Cantabria, en 1480, Antonio de Guevara procedía de una casa noble de las Asturias de Santillana. Fue segundón y como tal se le destinó a la carrera eclesiástica, aunque gracias a un tío suyo pudo educarse en la Corte, donde fue paje del príncipe Juan y de la reina Isabel. Al morir la reina entró en la Orden de San Francisco, en la que ascendió con celeridad. Su profesión religiosa no le apartó de la corte. Estuvo al servicio del emperador Carlos durante la Guerra de las Comunidades de Castilla, y este le premió su fidelidad nombrándole predicador real en 1521. Antonio de Guevara tenía entonces cuarenta años. Su fama de orador, escritor y humanista era ya muy grande en la Corte.

Muy importante fue la oportunidad que tuvo de viajar, por España y por el extranjero. Acompañó al Emperador en su viaje a Inglaterra en 1522, regresó después a España y en mayo de 1523 asistió al capítulo general de su orden en Burgos. Durante los años siguientes recorrió varias ciudades de Castilla junto al Emperador. Se hallaba en Valencia en 1525, como miembro de una comisión encargada de convertir a los moriscos del reino. A comienzos de 1527 Carlos V lo nombró su cronista oficial y se trasladó a Valladolid para participar en la junta de teólogos que debía dictaminar sobre las obras de Erasmo de Rotterdam. Fue consejero del Emperador y colaboró en la preparación de los discursos imperiales.

El 7 de enero de 1528 fue nombrado obispo de Guadix, pero sólo en 1529 obtuvo permiso real para marchar a esa diócesis; sin embargo, no permaneció allí muchos años. Acompañó al Emperador en la empresa de Túnez en 1535 y en 1536 visitó Roma y Nápoles. Después regresó a España. Actuó como predicador en el funeral de la Emperatriz en Toledo, en 1538. Continuó compartiendo su vida entre sus obligaciones cortesanas y sus deberes eclesiásticos. En 1537 había sido designado Obispo de Mondoñedo, pero la Corte le apartó de su nueva diócesis por largas temporadas.

2. Duroux, Rose (éd.): Les traités de savoir-vivre en Espagne et au Portugal du Moyen Âge à nos jours, Clermont-Ferrand, Association des Publications de la Faculté des Lettres et Sciences Humanes de Clermont-Ferrand, 1995. AMPUDIA DE HARO, Fernando: La civilización del comportamiento. Urbanidad y buenas maneras en España desde la Baja Edad Media hasta nuestros días Tesis Doctoral.Facultad de Ciencias Políticas y Sociología. Universidad Complutense de Madrid, 2004.

3. CAPITÁN DÍAZ, Antonio: «Educación, urbanidad y buenos modales en el siglo XVI español». De El Cortesano al Galateo» en Delgado, Buenaventura y RodríGueZ, Ma Luisa (coords.): Homenaje al Profesor Alexandre Sanvisens. Barcelona, Universidad de Barcelona, 1989. 
A pesar de sus compromisos cortesanos y eclesiásticos, dedicó siempre mucho tiempo a escribir y fue como escritor como alcanzó la fama. Fue un autor muy prolífico y su obra escrita fue muy divulgada. Aunque fue acusado por algunos humanistas de hacer gala de una erudición poco rigurosa, gozó en su época de gran predicamento, avalado por su influyente posición en la Corte. Caracterizaba a Guevara la intención de educar y moralizar deleitando. Sus libros trataban sobre los más diversos temas: Libro áureo de Marco Aurelio (Sevilla, 1528), Reloj de Príncipes (Valladolid, 1529), Aviso de privados y doctrina de cortesanos (Valladolid, 1539), Menosprecio de corte y alabanza de aldea (Valladolid, 1539), Una década de Césares, es a saber: Las vidas de diez emperadores romanos que imperaron en los tiempos del buen Marco Aurelio (Valladolid, 1539), Arte del Marear y de los inventores de ella: con muchos avisos para los que navegan en ellas. (Valladolid, 1539), Epistolas familiares (Valladolid, 1539 y 1541), Oratorio de religiosos y ejercicio de virtuosos (Valladolid, 1542) y Monte Calvario, primera y segunda parte (Valladolid, 1545 y1549). En 1541 promulgó unas Constituciones Sinodales que fueron muy importantes para su diócesis gallega. ${ }^{4}$

Falleció en Mondoñedo, Lugo, el 3 de abril de 1545, y fue enterrado en la catedral. Su espíritu fue plenamente renacentista por su afán de gloria y de fama. ${ }^{5}$

\section{LA MESA CORTESANA}

La doble condición de cortesano y de religioso que reunía Fray Antonio de Guevara se refleja muy bien en sus opiniones y consejos sobre la alimentación y en torno al comportamiento en la mesa. Siempre recomendaba prudencia y mesura, tanto al cortesano como al religioso, pues aunque unos y otros ocupaban posiciones muy diferentes en la sociedad y se movían por finalidades muy distintas, en ambos casos, como seres humanos civilizados y como buenos cristianos, debían comer con medida y comportarse en la mesa con buenos modos.

El tema de la cortesía era obligado para un escritor como Guevara que vivió muchos años en la corte y que dedicó a la vida cortesana una parte importante de su obra. Muy significativo es su libro Aviso de privados y doctrina de cortesanos, de 1539. Guevara reúne en este libro toda su experiencia de cortesano. La temática lo aproxima al Menosprecio de corte y alabanza de aldea, siendo el Menosprecio una continuación del Aviso, para el cortesano que quiera dejar de serlo, mostrándole el camino del retiro de la vida pública a la vida privada. No en vano la idea del retiro ya aparecía en el Aviso, en el capítulo XVI. ${ }^{6}$ El libro estaba dedicado a Don Francisco de los Cobos, secretario del Emperador. La obra puede considerarse dividida en un prólo-

4. De las obras de Guevara existen ediciones digitales: Proyecto Filosofía en español www.filosofia.org

5. BLANCO, Emilio: «Bibliografía de Fray Antonio de Guevara, O.F.M. (1480?-1545)» en El Basilisco, número 26, Oviedo 1999.

6. Costes, René: «Antonio de Guevara. Sa vie» y «Antonio de Guevara. Son oeuvre», Bibliothèque de l'École des Hautes Études Hispaniques, X-1 (1925), X-2 (1926). 
go y dos partes: una dedicada a los cortesanos (capítulos I al X) y otra, a los privados (capítulos XI al XX). ${ }^{7}$

La corte imperial de Carlos V, organizada sobre el modelo de la corte de Borgoña, alcanzó un nivel de esplendor y ritualización antes desconocido en España. ${ }^{8}$ La mesa reflejaba muy bien el simbolismo de poder, riqueza, abundancia y refinamiento de aquella corte. Vivir y prosperar en aquel ambiente no era misión sencilla, se requería conocimiento, habilidad, experiencia. Además se requería mucha prudencia, mesura y sensatez para no perder el autocontrol y caer en excesos y abusos de todas clases. La Corte era una gran oportunidad, que había que aprender a aprovechar bien, pero era asimismo una tentación permanente, a la que había que aprender a resistir. Era como un laberinto complicado, por lo que resultaba muy útil tener una buena guía.

La obra de Fray Antonio de Guevara, Aviso de privados y doctrina de cortesanos, trataba de dar respuesta al problema de vivir y medrar en la Corte, sin caer en ninguna de sus numerosas trampas, pretendía ser una guía de comportamiento del perfecto cortesano. Tiene además un gran valor como crónica histórica sobre los usos y costumbres de la corte y retrata muchas escenas y personajes del mundo cortesano. A diferencia de Castiglione y Boscán, que, de manera optimista, presentaban la corte como una oportunidad de mejorar la naturaleza humana, para Guevara, de manera pesimista, era un lugar de perdición, donde todos peligraban y podían acabar corrompidos, donde triunfaba el que conspiraba y engañaba y donde no eran las mejores personas las que ocupaban los mejores cargos. Sólo quien tenía ideas claras y una voluntad fuerte podía mantenerse incólume. Para ello era necesario tener mucha experiencia y, si no la tenía, podía el cortesano servirse de la experiencia ajena, bien fuese aprovechando las enseñanzas que la historia le aportaba o las que libros como Avisos le ofrecían. ${ }^{9}$

En su Aviso dedicó Guevara al tema de la alimentación el Capítulo VII, titulado «De la templanza y crianza que el Cortesano ha de tener cuando comiere a la mesa de los señores». ${ }^{10} \mathrm{El}$ cortesano modelo debía comportarse siempre con propiedad y la comida era una oportunidad perfecta para manifestar la calidad de la persona. Recomendación principal era mantener una cierta reserva y no prodigarse en exceso. Guevara aconsejaba a los cortesanos que no fueran de mesa en mesa, aceptando invitaciones. Advertía que era más honrado invitar que ser invitado y consideraba que lo justo era actuar unas veces como anfitrión y otras como huésped, siempre con medida y en atención a la oportuna correspondencia. Las personas que frecuentaban la corte

7. Libro llamado Aviso de privados y Doctrina de Cortesanos. Sevilla, Extramuros Editorial. 2007.

8. MARTíneZ Millán, José (coord.): La corte de Carlos V, Madrid, Sociedad Estatal para la Conmemoración de los Centenarios de Felipe II y Carlos V, 2000, 3 vols.

9. Morreale, Margherita: Castiglione y Boscán: El ideal cortesano en el Renacimiento español, Madrid, Impr. de S. Aguirre Torre, 1959, 2 vols. Serie Anejos del Boletín de la Real Academia Española, 1.

10. Aviso de privados y doctrina de cortesanos, compuesto por el Ilustre, y Reverendísimo Señor D. Antonio de Guevara, Obispo de Mondoñedo, Predicador, y Cronista, y del Consejo de su Majestad. Dirigido al Ilustre Señor D. Francisco de los Cobos, Comendador mayor de León, del Consejo de Estado de su Majestad. En Madrid, por la Viuda de Melchor Alegre, año MDCLXXIII, Capítulo VII, pp. 138-144. 
debían cuidar de no abusar de las invitaciones de anfitriones dadivosos, ya que a fuerza de sentarse a la mesa se adquirían vínculos de dependencia:

«Los que andan en las Cortes de los Príncipes, deben comer muchas veces en sus posadas, y pocas en las ajenas; porque el Caballero que anda de mesa en mesa, de la hacienda ahorra poco, y de la reputación pierde mucho. (...) Si para otras cosas se sufre que seamos rogados, o a lo menos para ir a comer por mesas ajenas, hemos de ser constreñidos. Siendo el Cortesano constreñido, y no habiéndose él ofrecido a comer, tanto servicio recibirá el que le convida como él merced en ser convidado: y de otra manera, más parecía mesa de pasajeros, que no convite de Caballeros. El día que uno se abate a comer a mesa de otro, aquel día se obliga a ser su siervo; porque dado caso que el comer sea por voluntad, el servicio ha de ser de necesidad.»

La hospitalidad era muy importante como signo social, tanto para el anfitrión como para el invitado. En la corte la mesa servía como elemento de distinción y los convites eran oportunidades muy reveladoras. Guevara aconsejaba presentarse debidamente al anfitrión y a la vez denunciaba algunas malas costumbres extendidas en la época, como sobornar a los criados para obtener mejores puestos en la mesa o mejores platos en la comida:

«Si por caso al Cortesano le viene un huesped nuevo, llévale consigo a que bese las manos al Caballero, con quien aquel día ha de ir a comer, diciendo, que es su deudo muy propinquo: lo cual no hace él por dársele a conocer, sino porque se queden ambos a dos allí a comer. Usan de otra cautela los tales, y es que halagan a los pajes primero, porque les den del buen vino, y sobornan al maestre sala, porque les sirva buen plato.»

La mesa era reflejo de la corte y de la sociedad. Muy importante era el orden de la mesa, ya que la mesa a la vez une y jerarquiza. Sentarse juntos manifestaba unidad, pero el lugar que cada uno ocupaba en la mesa reflejaba el orden social y el lugar que cada uno ocupaba en el mundo cortesano y en aquella ocasión en concreto, en función de su rango y de la relación que le unía con el dueño de la casa. Era esencial ocupar en la mesa el lugar justo, ni mayor ni menor:

«Acontece en las casas de los grandes señores, que concurren a la hora del comer muchos, y no pueden caber a la mesa todos, y en tal caso, ojalá pusiesen los tales tanta diligencia en tomar lugar cuando se sientan. Si por caso viene el Cortesano tarde a comer: es verdad que tiene empacho de entrar, no por cierto, que en su poca vergüenza, aunque esté llena la mesa, se asienta con otro a media silla. (...) Muy vencido es de la gula, y aun es muy gran poquedad de la persona, por una parte querer tener en buen lugar la sepultura, y por otra asentarse en cualquier lugar de la mesa.»

Guevara criticaba a los cortesanos que se aprovechaban de las mesas ajenas. Mejor era comer sencillamente en la propia casa que ir de mesa en mesa hasta acabar haciendo el ridículo. Se buscaba comer bien y con frecuencia se comía mal y con incomodidad:

«El que no tiene qué comer, lícito es adonde quiera que pudiere irlo a buscar: mas el Cortesano que tiene honestamente qué comer, gran afrenta le es andar de mesa en mesa. El que va a comer fuera de su posada, a las veces le cabe lugar bajo silla quebrada, tobelleta sucia, cuchillo boto, agua caliente, vino aguado, manjar duro; y lo que más de todo, que le 
muestran todos ruín rostro. A mi parecer, el que con tales condiciones quiere ir fuera de su casa a comer, más lícito le sería honestamente en su casa ayunar.»

En opinión de Guevara era más cuerdo gozar de la privacidad de la propia casa, llevando una vida mucho más cómoda, agradable y libre, que andar buscando acomodo en lugares públicos, persiguiendo una mal entendida sociabilidad cortesana. Muy significativa de esa vida austera y ordenada es la comida que presentaba como ideal, comer olla de carne y pan blanco, beber vino blanco o tinto, comer caliente, con manteles limpios y cuchillos bien afilados:

«El que en su posada puede alcanzar a comer una olla de carne, y unos manteles limpios, y el pan que sea blanco, y el cuchillo que esté amolado, y un poco de lumbre en el Invierno: diría yo, que el tal si se huelga de andar de botillería en botillería, que o es por sobra de avaricia, o falta de cordura. El que come en su posada, si a la sazón es Verano, come medio desnudo, asiéntase a su contento, bebe frío, ojéanle las moscas, tiene el patio regado, y en acabando de comer, está en su mano retraerse a sestear. Si por caso es Invierno, desnúdase, si está mojado, descálzase, si está frío, arrópase con un zamarro, y lo que come cómelo caliente, y zumoso, bebe vino blanco o tinto, y después que ha comido, no tiene que aguardar Palacio. Tales, y tan grandes privilegios como son éstos a favor de la libertad, por dineros debería el buen Cortesano comprar, cuanto más por miseria de una comida no dejarlos perder.»

Pero la vida pública nunca debía descuidarse. La mesa cortesana era una mesa de apariencia, prestigio y sociabilidad. Era una mesa para dar imagen y para fomentar la relación con los demás. Por tanto, muy importante era también, en opinión de Guevara, que el cortesano guardara las buenas maneras en la mesa, tanto en atención a su propia imagen y calidad, como en consideración hacia los demás comensales. Daba detallados consejos de buen comportamiento, tanto en positivo como en negativo, lo que debía hacerse y lo que debía evitarse, tanto palabras como acciones, gestos, posturas:

«Ya que el Cortesano se determinare de ir a comer con algún señor, debe mirar que por loar los manjares de uno, no diga mal del plato que hace otro; porque especie es de traición osarnos poner a murmurar de aquel con quien nos sentamos a ver comer. Después de asentado a la mesa, debe el Cortesano estar asosegado, comer limpio, beber templado, y hablar poco; por manera, que los que allí se hallaren le loen de muy sobrio en el beber, y de muy sin perjuicio en el hablar. Por comer limpio entendemos, no se sonar en pañizuelo, no se echar sobre la mesa de codos, no comer hasta acabar los platos, ni murmurar de los cocineros; porque muy gran infamia es para un Cortesano notarle de goloso, y acusarle de sucio. Hay algunos tan domésticos, que no contentos con los manjares que le sirven en sus platos, arrebatan también lo que sobra en los platos de los otros; por manera, que con una manera de truhanería, se precian de ser absolutos en pedir, y disolutos en el comer. Guárdese el curioso Cortesano de poner en la mesa los codos, de mascar con dos carrillos, de beber con dos manos, de estar arrostrado sobre los platos, de morder el pan entero a bocados, de acabar el manjar primero que todos, de lamer a menudo los dedos, y de dar en los potajes grandes sorbos; porque tal manera de comer, uso es de bodegones, y no de mesas de señores. Si de todos los manjares que le pusieren delante no pudiere comer, a lo menos no los deje de probar, y aun loar, porque los señores, a cuya mesa comen, sienten por afrenta si sus convidados no loan los manjares que les dan, y aun a los oficiales que lo guisan.» 
Arte cortesano por excelencia era la cultura del elogio, que siempre debía estar presente en la mesa. Alabar al anfitrión, a sus comidas, a sus cocineros era obligación de todo buen comensal. Podría decirse que la alabanza, aunque no siempre merecida, era el pago esperado por la invitación a comer:

«El que se abate a comer a mesa ajena, aunque sepa que dice mentira, es obligado de loar a los señores de magnánimos, y a sus oficiales de muy curiosos. No inmérito decimos, que alguna alabanza ha de ir envuelta con alguna mentira, pues vemos algunas mesas de señores tan mal proveídas, que las comidas que allí dan, mas son para víspera de purga, que no para día de Pascua. (...) Más vanagloria toman los señores de tener un gran cocinero en su cocina, que de tener a un valeroso Alcaide en su fortaleza.»

Fundamental era para el buen cortesano saber comer y saber beber, hacerlo siempre con moderación, prudencia y elegancia. Y saber comportarse amablemente, evitando quejas, críticas y comentarios desagradables, en atención al anfitrión y también a sus criados:

«Prosiguiendo, pues, a nuestro intento debe el sobrio Cortesano beber a la mesa ajena poco, y lo que bebiere sea muy aguado; porque el vino aguado ni emborracha a los que lo beben, ni escandaliza a los que lo miran. Si por caso el vino estuviere aguado o ácido, y el agua no estuviere fría, no debe el curioso Cortesano quejarse luego allí a la mesa, porque sería afrentar a los criados, y lastimar al Señor.»

Especial cuidado había que tener con el vino. Guevara censuraba a los que exigían determinados vinos y mucho más a los que se excedían bebiendo y rivalizaban en beber más que los demás. Si en el mundo cortesano la competencia era buena en otras actividades, los desafíos en la bebida los consideraba Guevara un «gran sacrilegio». En su opinión eran muy penosas las consecuencias de los excesos:

«En casa ajena ninguno ha de tener licencia de pedir vino blanco, si le dieren tinto, ni pedir tinto si le dieren blanco; porque el verdadero Cortesano, no ha de saber a qué sabe el vino. Desfiarse los mancebos Cortesanos a correr un trecho, a saltar un salto, a tirar la barra, a danzar una baja, y abatir las piernas a un caballo en la carrera: decimos que es lícito, y aun necesario, mas desasirse a beber a dautan el vino, sería en el Cortesano gran sacrilegio. (...) Vemos a infinitos, que escapan de los banquetes, y comidas, regoldando lo que comieron, y rebesando lo que bebieron.»

Recomendaba Guevara abstenerse del vino o al menos beberlo con moderación. Y se manifestaba contrario a que los cortesanos presumieran de poseer una buena cultura del vino, comentando sus virtudes, como parece que en aquellos tiempos se había puesto de moda en los círculos de la Corte imperial:

«El que bebe agua, y no bebe vino, tiene muy gran libertad; porque el desordenado beber del vino, no sólo perturba los juicios, mas aun es muy mullidor de los vicios. Estando a mesa ajena, sobrada curiosidad es, disputar cuál de los vinos es más suave, o cuál más blando, o cuál más hecho, o cuál dulce, cuál más añejo, cuál más nuevo, cuál aloque o cuál más cubierto, cuál más sano, o cuál más oloroso; porque al tabernero pertenece saber cuáles son los mejores vinos que al Cortesano no, sino los buenos caballos. Hermosa curiosidad es, no sólo beber agua, mas aun no la poder beber en vasija que haya caído vino. Guárdese el que es de otro convidado, que en el beber, no sea tanta su desvergüenza, que 
cada vez beba toda la taza: porque el buen Cortesano, ni ha de beber hasta más no poder, y mucho menos hasta más no tener.»

La mesa era un importante escenario de convivialidad. Era de gran importancia saber conversar en la mesa con moderación, prudencia y elegancia, evitando temas enojosos y polémicos, que pudieran desencadenar conflictos. No consideraba de buen tono criticar la comida o hablar de guisados. Para Guevara la mesa no debía estar al servicio de los placeres gastronómicos, sino que debía ponerse al servicio de razones sociales y políticas:

«Al tiempo del comer, no del hombre cuerdo levantar pláticas, ni tomar con otros porfías, ni hablar palabras feas, y mucho menos debe dar allí grandes risadas; porque si es malo notar a uno de goloso, peor es notarle de chocarrero. Poco aprovecharía que fuese el Cortesano corto en el comer, y largo en el hablar; porque en las mesas de los señores: si se huelgan con unos convidados más que con otros es, no porque van a comer, sino por oírlos mentir. (...) Cuando a la mesa de un señor se moviere plática, sobre qué manjares son más sabrosos, qué cocineros hay en la Corte más curiosos, qué potajes hay más nuevos, y de dónde son los capones más gruesos, no cure el buen Cortesano de decir en la tal disputa lo que sabe, ni menos lo que siente; porque cuán honesto le es saber bien la plática de las armas, tan infame le sería saber cómo se guisan las golosinas. Comiendo yo con un Prelado, oí a un Caballero alabarse, que sabía hacer siete maneras de tortadas, y cuatro de escabeches, y ocho de salsas, y diez de hacer frutas, y doce de aderezar huevos, y no era nada oírselo decir, con vérselo representar, porque parecía que cada manjar estaba haciendo con sus manos, y aun probándole con la lengua.»

En el siglo XVI la corte del Emperador Carlos había hecho del banquete un símbolo máximo de poder y placer. A Carlos V le gustaba comer mucho y bien y sus cortesanos siguieron su ejemplo. ${ }^{11}$ La moda de los banquetes triunfó en la corte española y en muchas otras mesas. Como afirmaba el médico del Emperador Luis Lobera de Ávila en su Vergel de Sanidad o Vanquete de Nobles Caballeros, de 1530: «Porque los caballeros y señores, así de España y de Francia y de Alemania como de Italia y otras partes, usan ahora y tienen mucho en costumbre de hacerse los unos a los otros banquetes y beber «autant», que ahora dicen, diré las cosas que el buen banquete ha de llevar y los daños que de usarlos mucho se siguen.» ${ }^{12}$ Algo parecido decía el famoso humanista Juan de Valdés en su Diálogo de la Lengua, escrito en 1533: «...Al juego, al vestir, al vanquetear, que son tres cosas que con la venida de Su Majestad en España an crecido en tanta manera que se siente largamente por todas partes...». ${ }^{13}$

11. PÉreZ SAMPER, María Ángeles: «La alimentación en tiempos del Emperador: un modelo europeo de dimensión universal», en CASTEllano CASTEllano, Juan Luis, y SÁNCHEZ-Montes GonZÁleZ, Francisco: Congreso Internacional Carlos V, Europeísmo y Universalidad, Madrid, Sociedad Estatal para la Conmemoración de los Centenarios de Felipe II y Carlos V y Universidad de Granada, 2000, vol. V, pp. 497-540.

12. López PiÑero, José María: El Vanquete de Nobles Cavalleros (1530), de Luis Lobera de Ávila y la higiene individual del siglo XVI, Madrid, Ministerio de Sanidad y Consumo, 1991,Ed. facsímil, p. 13.

13. VALDÉS, Juan de: Diálogo de la Lengua, Madrid, Espasa Calpe, S.A., Colección Austral, 1964, p. 228. 
A pesar del esplendor de los banquetes imperiales, Guevara tenía una visión muy negativa de la mesa cortesana y censuraba a los cortesanos que se dejaban llevar de los placeres gastronómicos. En el Capítulo XVIII titulado Que los Privados de los Príncipes se deben mucho guardar de no ser derramados en hacer, ni recibir desordenados convites. Es capítulo notable contra los banquetes, una vez más ponía en guardia a los cortesanos sobre los excesos en el comer. ${ }^{14}$

Comenzaba por hacer una serie de reflexiones sobre la necesidad de la comida para todos los seres vivos, distinguiendo entre la simple nutrición y el hecho cultural de alimentarse, censurando que los seres humanos hubieran convertido esa necesidad en un placer, pasando del sustento al regalo, y cometiendo con frecuencia toda clase de excesos:

«Uno de los graves censos que echó naturaleza humana sobre sí mismo fue, que no pudiesen los hombres vivir, si no fuese con el ejercicio del comer: por manera, que si mil años viésemos a un hombre comer, le veríamos siempre vivir. (...) Yo confieso, que para nos poder sustentar, es necesario el comer: mas es de saber, que no está el daño de la gula en lo que se come por necesidad, sino por voluntad: porque ya no comen los hombres para sustentarse, sino para regalarse. El hombre que se deja vencer de la gula, no sólo atormenta el cuerpo, mas aun pone mácula en la conciencia: porque los hombres glotones, y golosos, primos hijos de hermanos son de los vicios. (...) La variedad de los manjares, ¿qué otra cosa es, sino un importuno mullidor de los torpes pensamientos?».

Añadía a continuación varios ejemplos tomados de las vidas de santos, San Jerónimo, San Pablo, San Agustín. Su propósito era destacar la importancia del control del cuerpo, relacionando, como era habitual entre los moralistas de la época, gula con lujuria. El control del cuerpo era fundamental, pues los excesos perjudicaban la salud del individuo que los cometía, y también perturbaban el orden de la sociedad. De manera irónica consideraba Guevara más peligroso comer en exceso que pasar necesidad. En su opinión, los glotones en el pecado llevaban la penitencia:

«Cuanto estos gloriosos Santos no se podían valer de la ardiente concupiscencia, con el continuo ayunar, ¿qué harán los voraces, y glotones que nunca cesan de comer? Podemos tener por cierto, que a estos cuerpos mortales, y a los pensamientos carnales, tanto más los tenemos sujetos, cuanto menos los consintiéremos ser regalados: porque por muy bravo, y encendido que sea el fuego, muy en breve se torna todo en ceniza si dejan de echarle leña. El desordenado comer, no sólo es injusto para la vida, mas aun enfermo para el cuerpo: porque al fin a más ricos hemos visto morir por lo que les sobra, que no a pobres por lo que les falta. A mi parecer, el pecado de la gula no hay necesidad, que le castiguen por justicia pues el mismo a sí mismo se da la penitencia: y que sea esto verdad, tomemos juramento a un hombre muy goloso, qué tal se siente después de muy harto, y hallaremos que tiene la boca seca, el cuerpo pesado, la cabeza atónita, el estómago acedo, los ojos dormidos, ahito de comer, y deseoso de más beber.»

Como buen humanista, en una alarde de erudición a la que era tan aficionado, Guevara añadía una serie de ejemplos tomados de la Antigüedad clásica.

14. Aviso de privados y doctrina de cortesanos, en Madrid, por la Viuda de Melchor Alegre, año MDCLXXIII, Capítulo XVIII, pp. 208-220. 
Denunciaba los excesos en el comer no sólo por el mal moral sino porque perjudicaban gravemente la salud. En esto coincidía con los médicos de la época. Luis Lobera de Ávila, en su libro Vergel de Sanidad o Banquete de Nobles Caballeros, aconsejaba igualmente contención en la mesa. ${ }^{15}$ Decía Guevara que los banquetes minaban la salud de muchos cortesanos:

«En este caso, sin comparación son más templados los animales que no los hombres, pues vemos que ningún animal come más de hasta hartar, y el hombre come hasta hartar, y aun hasta regoldar. (...) A la salud ninguna cosa la conserva tanto, como es el trabajo, y ninguna cosa la destruye tanto como es el regalo. (...) Los médicos que entre nosotros andan, no entran por las puertas de los pobres que trabajan, sino por las de los ricos que huelgan. Miento, sino vi a un Caballero amigo mío que era, y aun por ventura deudo, el cual como se purgase, y yo por enfermo, le visitase, él me confesó, que estaba para un banquete desafiado, y que no se purgaba por estar malo, sino por estar para comer más dispuesto. Después que esto pasó, no pasaron seis días, que yo le torné a visitar, porque estaba asaz malo, no de ayuno, sino de ahito, de lo cual resultó que para comer se purgó una vez, y para se desahitar se purgó tres, y en el banquete tardaron en comer cuatro horas, y costóle a él estar en la cama sesenta días. En darle esta enfermedad Dios a este Caballero, no sólo no le hizo injuria, sino que le hizo gracia de la vida: porque si es grave, y muy grave el pecar, es grave, y gravísimo aparejarse para pecar.»

Junto a los males morales y físicos, Guevara denunciaba los perjuicios económicos. Los banquetes causaban la ruina de muchos por los grandes gastos que implicaban. Ofrecer un banquete suponía la compra de gran cantidad de productos y muy caros, muchos recursos humanos para prepararlo y servirlo, grandes dispendios en decoración del comedor y de la mesa, gastos adicionales en los entretenimientos que acompañaban el banquete, como música, teatro, baile:

«El mucho comer, no sólo es peligroso para la conciencia, y dañoso para la salud de la persona, mas aun es polilla para la hacienda, porque ningún glotón toma tanto placer en el comer de los manjares, como es el sinsabor que toma cuando pide cuenta a los despenseros. Placer es comer con gana, mas muy gran sinsabor es echar mano a la bolsa: y no inmérito decimos, que es muy gran sinsabor echar mano a la bolsa, porque si los manjares entran con dulzura en el estómago, los dineros aunque salen de la bolsa, arráncanse del corazón. (...) Querer, pues, hablar de los banquetes, a nuestra nación nuevamente traídos, más es cosa para llorar, que no para escribir.»

También censuraba Guevara el afán de las novedades, pues las modas gastronómicas rompían las viejas costumbres y tradiciones más austeras e introducían toda clase de invenciones y lujos, procedentes de todas las partes del mundo. Sus observaciones constataban la transformación que había experimentado la cocina cortesana

15. SÁnChez GrAnJel, Luis: «Luis Lobera de Avila», en Estudios de Historia de la Medicina Española, Universidad de Salamanca. Volumen 1, Número 4 (1959). Y «Humanismo y Medicina. El capítulo médico en la obra literaria de fray Antonio de Guevara», en Cuadernos de Historia de la Medicina Española, IX (1970), pp. 99-119. GonZÁLEZ DE AMEZÚA, Agustín: «Tres humanistas españoles del siglo XVI frente a la Medicina», Medicamenta, VIII (1942), pp. 227-230. Recogido en Opúsculos histórico-literarios, Madrid, RAE, 1951. 
de la Monarquía Española, hacia una creatividad y un cosmopolitismo que reflejaba, por una parte, las modas gastronómicas de las cortes renacentistas, $\mathrm{y}$, por otra parte, la complejidad territorial de la herencia recibida por Carlos V, así como su expansión mundial, por Europa, América, África y Asia:

«Miento, si no vi en un banquete servirse cuarenta y dos platos, y en otro banquete vi en día de carne dar barbos enlardados con mechas de tocino. En otro banquete vi dar lechones rellenos con tarazones de lampreas, y de truchas. En otro banquete también vi hecho de seis a seis, sobre apuesta que bebería cada uno tres azumbres, con tal que durase seis horas la comida, y el que perdiese pagase toda la costa de la comida. Vi también otro banquete, en el cual se pusieron tres mesas a unos mismos convidados, una a la Española, otra a la Italiana, y otra a la Flamenca: y a cada mesa se sirvieron veintidós manjares. Vi también otro banquete, en el cual sobre acuerdo se comieron manjares, que los tratamos, mas no los comemos, es a saber, asadura de caballos, cogollos de sauco, gato montés en escabeche, culebras asadas, tortugas cocidas, ranas frías, y otros diversos manjares, que les vi allí comer, aunque no los supe conocer. ¿Quién será el que leyere esta escritura, y viere lo que en los banquetes ahora pasa, que el corazón no se le parta, y riegue con lágrimas su cara? Las especias que vienen de la Isla de Calicú, y los banquetes que nos envió Francia, aquello ha destruido a nuestra nación toda: porque antiguamente no había en España otra especia, sino azafrán, y comino, y ajo, y si quería un amigo dar a otro amigo una buena comida, el banquete era una buena olla de carnero, y vaca, y era gran cosa si mataban una gallina.»

La moda de los banquetes triunfaba en la corte, pero se contagiaba también a otras capas de la sociedad, andando todos desbordados por afanes gastronómicos:

«iAy dolor, que no es ya como solía, sino que si un oficial, o escudero o plebeyo, convida a otro de comer, aunque sepa vender la capa, o ayunarlo una semana, ha de pasar a lo menos de seis, o siete manjares la comida! Qué cosa es ver dos, o tres días antes la casa donde el banquete se ha de hacer, avisando a los cocineros, apercibiendo a los Maestresalas, amenazando a los pajes, ordenando los manjares, visitando los botilleros, aparejando los aparadores, y probando los vinos: por manera que ojalá la mitad de la solicitud que ponen, cuando han de banquetear, pusiesen cuando se han de ir a confesar. Después de pasado el banquete, pregunto ahora yo, ¿qué es lo que queda? Lo que queda es, los dueños desvelados, los Maestresalas cansados, los cocineros molidos, la casa sucia, la ropa grasienta, y alguna pieza de plata hurtada, y lo que más es, que algunas veces queda el huesped despechado de la gran costa, y los convidados aún van descontentos de la comida.»

Guevara condenaba los banquetes, los consideraba un peligro que corría la humanidad en todos los tiempos y muy especialmente en el suyo, el siglo XVI. Consideraba «el vicio de la gula enojoso, peligroso, y costoso» y le achacaba toda clase de malas consecuencias para el cuerpo y para el alma. Para condenar los banquetes se apoyaba en la historia, la sagrada y la profana, y aprovechaba la circunstancia para hacer alarde de erudición.

Acumulaba ejemplos de la Biblia, desde Adán y Eva, que perdieron a la humanidad por una manzana, y siguiendo por Esaú y Jacob, Abasalón, Asuero, Job, Baltasar:

«A todos estos que habemos aquí puesto, y a otros infinitos que dejamos de poner, mejor les fuera comer a solas, que morir acompañados. Noten bien los golosos esto que quiero decir, y es, que el vicio de la gula es enojoso, peligroso, y costoso; digo que es enojoso, por el cuidado que tiene cada hora de buscar de comer, es peligroso para la salud 
conservar, es costoso por lo mucho que ha de gastar: por manera, que es breve el deleite de la gula en que nos deleitamos, y después, y antes son infinitos los males que por ella padecemos.»

Se apoyaba Guevara en los filósofos clásicos, como Aristóteles, y en los profetas del Antiguo Testamento, como Isaías. Todas las fuentes de autoridad de la época eran invocadas para avalar su mensaje de moderación en la comida y en la bebida. Añadía ejemplos del mundo antiguo, de Grecia, Roma, Egipto. De Roma destacaba la numerosa legislación prohibiendo los excesos en los banquetes. A la legislación sumaba también varios ejemplos tomados de la historia de Roma, tanto de austeridad, el caso de Cayo Graco, como de abundancia, así citaba a Marco Mancio, Lentulo, César, Sila, Escebola y Emilio, símbolos de los grandes glotones que existieron en la Roma clásica.

Todo este despliegue de erudición sobre el pasado lo ponía Guevara al servicio del presente, pues los ejemplos trataban de establecer una pedagogía del orden y de la moderación, prohibiendo toda clase de excesos. No se trataba de hacer historia, sino de enseñar moral, utilizando el recurso de la historia. La Historia era para Guevara maestra de la vida. Los consejos tenían además trascendencia política, pues se hallaban dirigidos al mundo cortesano, desde el que se regía el conjunto de la sociedad:

«Viniendo, pues, al propósito, el fin porque habemos dicho todo lo sobredicho, es para avisar a los Privados de los Príncipes, se guarden de ser en este vicio de la gula notados; porque muy gran nota es en un Privado, en el cual tiene puestos los ojos todo el Pueblo, que sea voraz en el comer, y desordenado en el beber. A los Privados más que a otros conviene, que sean en su comer templados, y en su beber muy reglados; y la causa de esto es, que como tengan con ellos muchas cosas que negociar, y ellos tengan graves negocios de la República que expedir, cosa es muy cierta, que después que estén muy hartos, no estarán hábiles para negocios; porque el mucho comer acarrea sueño, y el mucho beber embota el juicio. (...) Por bravo, o doméstico que sea un animal, jamás deja de ser animal, sino es el hombre, que muchas veces no sabe si es hombre; porque el comer, y el beber demasiado, enajena al hombre de sí mismo.»

Si los convites eran malos para todos, especialmente peligrosos y dañinos eran para los príncipes, los privados de los príncipes y para los cortesanos en general. Cuanta mayor era la responsabilidad de un personaje, mayor debía ser el control que tuviera sobre sí mismo. Aunque el banquete pudiera tener ventajas como exponente de poder, prestigio y distinción eran muchos los peligros que entrañaba, morales, físicos, económicos y también políticos. En tiempos del Emperador Carlos, tan aficionado a los placeres de la mesa, la censura de Fray Antonio de Guevara contra los banquetes resultaba muy significativa:

«A los Privados de los Príncipes, menos que a otros les conviene hacer grandes, y costosos convites; porque tienen sobre sí tantos veedores, que dicen unos, que no hacen aquellos convites, sino de lo que les presentan, y otros dicen, que no los hacen, sino de lo que roban. (...) Aviso, asimismo, al Privado del Príncipe, que mire bien de quien se fía, y a los que a su mesa pone; porque si son cuatro los convidados, el uno va a comer, y los tres a le acechar (...). Deben mucho advertir los Privados de los Príncipes, en que si son regalados en el comer, no sean desenfrenados en el hablar; porque los convidados que allí se hallaren, ténganle por dicho, que los manjares que les dieren llevarán en el estómago, mas las 
palabras sobradas que le oyeren, depositarán en el corazón. (...) Aconsejo, y amonesto a los Privados de los Príncipes, que se guarden, no sólo de hacer banquetes, mas aun de recibirlos; porque se han de tener por dicho, que son muy pocos los que los aman, y muy muchos los que los aborrecen, y podría de aquí suceder, que otro hiciese la costa, y él escotase la vida. (...) Sobre todas las cosas aviso, amonesto, y ruego a los oficiales de los Príncipes, no quieran vender, ni trocar, ni empeñar su libertad; porque el día que se dieren a banquetear, o a presentes recibir, o familiaridades estrechas tomar, o en bandos, y pasiones se meter, pocas veces harán lo que quieren, y muy muchas lo que no deben.»

\section{LAS MESAS DE LA ALDEA}

Menosprecio de corte y alabanza de aldea, publicada en Valladolid en 1539 fue otra de las obras más famosas de Fray Antonio de Guevara. ${ }^{16}$ El libro tuvo gran repercusión. Influyó en diversos autores españoles, como Pedro de Navarra en su Diferencia de la vida rústica a la noble, de 1567, y fue traducido a varias lenguas, al francés (Lyon, 1542), al inglés (Londres, 1548), al italiano (Florencia, 1601) y al alemán (Ginebra, 1604).

El tema de la corte, con sus fortunas y adversidades, aproximaba la obra al Aviso de Privados, siendo el Menosprecio la obra que el cortesano debía leer para que le marcase los pasos a seguir tras el abandono de la corte. Esta preocupación moral de oponer las virtudes de la vida de la aldea a los vicios de la corte se encontraba también presente en las Epistolas. Guevara, como eclesiástico, consideraba que sólo en el seno del cristianismo, y sometido a las normas de la Iglesia Católica, se podía realizar el ser humano en su plenitud moral. Conectaba de esta forma esta obra con las reflexiones posteriores del Oratorio, donde la vida monástica, como ejemplo de recogimiento y de dominio de las pasiones, podía llevar a alcanzar la serenidad de una vida más elevada. El desprecio del mundo y el recogimiento, en la aldea o en el monasterio, llevarían además al ser humano a vivir libre de todo engaño y de todo desengaño.

Es evidente en la obra la tradición clásica del Beatus ille, tan celebrada por Virgilio y Horacio. Pero frente a estas propuestas ideales, que llegaron a España a través del humanismo italiano, la propuesta de Guevara, más concreta, estaba dirigida al cortesano que se encontraba en un ambiente determinado, la corte del Emperador Carlos V. La aldea de Guevara era el contrapunto a la corte española, tan bien conocida por él, era también la nostalgia de su querido pueblo de las Asturias de Santillana. ${ }^{17}$

16. Libro llamado Menosprecio de corte y alabanza de aldea. Dirigido al muy alto y poderoso Señor Rey de Portugal, don Juan, tercero de este nombre. Compuesto por el ilustre señor don Antonio de Guevara, Obispo de Mondoñedo, predicador y cronista y del Consejo de Su Majestad. Muestra el autor en este libro más que en ninguno de los otros que ha compuesto la grandeza de su elocuencia y la delicadeza de su ingenio. Va al estilo de Marco Aurelio porque el autor es todo uno. Posui finem curis: spes et fortuna valete. Año MDXXXIX. Con Privilegio. Fue impreso en la muy leal y muy noble villa de Valladolid por industria del honrado varón impresor de libros Juan de Villaquirán, a dieciocho de junio. Año de mil y quinientos y treinta y nueve. Edición actual Menosprecio de corte y elogio de aldea. Sevilla, Signatura Ediciones de Andalucía, 2005.

17. REDONDO, Agustín: «Du Beatus ille horacien au Mépris de la cour et éloge de la vie rustique d'Antonio de Guevara », en L'Humanisme dans las lettres espagnoles, París, 1979, pp. 252-265. 
Guevara tenía una opinión negativa y pesimista del mundo cortesano. Frente a los peligros de la corte Guevara proponía como solución moral la vida sencilla y retirada de aldea. Sólo después de conocer los peligros de la corte el verdadero sabio se daba cuenta de que la verdadera libertad para ejercer una vida virtuosa sólo podía conseguirse en una aldea. Así, la aldea no era sólo el lugar en el que descansar de los deberes políticos del hombre de corte, era sobre todo el puerto de salvación, para alcanzar una vida mejor, prólogo de la vida eterna.

Guevara pretendería también hacer una llamada al regreso al campo. A comienzos del siglo XVI se produjo en tierras de Castilla un considerable crecimiento de la población urbana. Los hidalgos de escasa renta y muchos campesinos abandonaban el campo y marchaban a las ciudades, especialmente a la corte, con la esperanza de encontrar buenas oportunidades. Guevara pretendería retener a los hidalgos en el campo, intentando con ello frenar el alza del poder del dinero y conseguir así esquivar la crisis económica y social que se apuntaba. La corte era para la nobleza, no era para el hombre normal y corriente, que debía seguir ocupado en sus trabajos. Sería desde un punto de vista económico y social una obra que avisaba del cambio que se estaba produciendo a causa de la progresiva sustitución del mundo agrario, el campo, por el mundo mercantil y por el mundo político, la ciudad. Los arbitristas seguirán esta línea hasta sus últimas consecuencias. ${ }^{18}$

Se considera la obra compuesta por tres partes: una de generalidades (capítulos I al IV); otra indicando los privilegios o ventajas de la vida en la aldea y los males e inconvenientes de la vida en la corte (capítulos V al XVII); y otra final en la que el autor lamenta haber vivido en la corte por los daños que esto le ocasionó, y se despide para siempre del mundo (capítulos XVIII al XX).

En el capítulo V, titulado: «Que la vida de la aldea es más quieta y más privilegiada que la vida de la corte», Guevara, entre otras muchas cosas positivas de la aldea, hacía un gran elogio del vino en su entorno natural. Uno de los alimentos básicos de la época dejaba en la aldea de ser un peligro, como era en la corte, y se convertía en una legítima fuente de placer, que abarcaba todos los pasos, desde contemplar la viña a beber el vino:

«Es privilegio de aldea que el que tuviere algunas viñas, goce muy a su contento de ellas, lo cual parece ser verdad en que toman muy gran recreación en verlas plantar, verlas binar, verlas descubrir, verlas cubrir, verlas cercar, verlas bardar, verlas regar, verlas estercolar, verlas podar, verlas sarmentar y sobre todo en verlas vendimiar. El que mora en el aldea toma también muy gran gusto en gozar la brasa de las cepas, en escalentarse a la llama de los manojos, en hacer una tinada de ellos, en comer de las uvas tempranas, en hacer arrope para casa, en colgar uvas para el invierno, en echar orujo a las palomas, en hacer un aguapié para los mozos, en guardar una tinaja aparte, en añejar alguna cuba de añejo, en presentar un cuero al amigo, en vender muy bien una cuba, en beber de su propia bodega, y sobre todo en no echar mano a la bolsa para enviar por vino a la taberna. Los que

18. REDONDO, Agustín: Antonio de Guevara (1480?-1545) et l'Espagne de son temps. De la carrière officielle aux oeuvres politico-morales, Ginebra, Droz, 1976. 
moran fuera del aldea no tienen manojos que guardar, ni cepas que quemar, ni uvas que colgar, ni vino que beber, ni aun arrope que gastar; y si algo de esto quieren tener, a peso de oro lo han de comprar.»

En el siguiente capítulo, el capítulo VI, titulado «Que en el aldea son los días más largos y más claros, y los bastimentos más baratos» hacía Guevara el elogio del otro gran alimento básico por excelencia, el pan, un pan bueno y verdadero, de una calidad que en la corte no podían ni imaginar, un pan para disfrutarlo desde el campo a la mesa, un pan bien aprovechado, que llegaba para todos:

«Es privilegio de aldea que el que morare en ella tenga harina para cerner, artesa para amasar y horno para cocer, del cual privilegio no se goza en la corte ni en los grandes pueblos, a do de necesidad compran el pan que es duro, o sin sal, o negro o mal lludido, o avinagrado, o mal cocho, o quemado, o ahumado, o reciente, o mojado, o desazonado, o húmedo; por manera que están lastimados del pan que compraron y del dinero que por ello dieron. No es así, por cierto, en el aldea, ado comen el pan de trigo candeal, molido en buen molino, ahechado muy despacio, pasado por tres cedazos, cocido en horno grande, tierno del día antes, amasado con buena agua, blanco como la nieve y fofo como esponja. Los que viven en el aldea y amasan en su casa tienen abundancia de pan para su gente, no lo piden prestado a los vecinos, tienen que dar a los pobres, tienen salvados para los puercos, bollos para los niños, tortas para ofrecer, hogazas para los mozos, ahechaduras para las gallinas, harina para buñuelos y aun hojaldres para los sábados».

En el mismo capítulo VI se celebraba también la alimentación de la aldea, su sencillez llena de calidad, y se alababa el ambiente de tranquilidad y comodidad en que podían hacerse las comidas, que en opinión de Guevara serían buenas comidas, pues cumplirían las tres reglas de oro: comer en el momento oportuno, eligiendo los alimentos preferidos, y en buena compañía de amigos verdaderos:

«Es privilegio del aldea que todos los que moran en ella coman a do quisieren y a la hora que quisieren, lo cual no es así en la corte y grandes pueblos, ado les es forzado comer tarde y frío y desabrido, y aun con quien tienen por enemigo. ¡Oh!, bendita tú, aldea, a do comen al fuego si es invierno, en el portal si es verano, en la huerta si hay convidados, so el parral si hace calor, en el prado si es primavera, en la fuente si es Pascua, en las eras si trillan, en las viñas si plantan majuelo, a solas si traen luto, acompañados si es fiesta, de mañana si van camino, olla podrida si vienen de caza, todo cocido si no tienen dientes, todo asado si quieren arreciar, a la tarde si no lo han gana, o muy temprano si tienen apetito. Tres condiciones ha de tener la buena comida, es a saber: comer cuando lo ha gana, comer de lo que ha gana, comer con grata compañía; y al que faltaren estas condiciones, maldecirá lo que come y aun a sí mismo que lo come».

Esta atractiva vida privada de la aldea no era, sin embargo, patrimonio de todos los aldeanos, sino más bien de una pequeña y privilegiada minoría, que se hallaba en condiciones de vivir tranquilamente, disfrutando de los placeres del campo, mientras la inmensa mayoría de campesinos trabajaban duramente, sin demasiadas ocasiones de gozar de la bucólica estampa dibujada por Fray Antonio de Guevara. 


\section{LA MESA DE MONASTERIOS Y CONVENTOS}

La mesa cortesana representaba el ideal gastronómico. Se esperaba de ella siempre abundancia y refinamiento. La realeza y la nobleza comían mucho y comían bien. En el extremo opuesto se hallaban las mesas de las clases populares, y las mesas de monasterios y conventos. Unos por obligación, los aldeanos, los otros por devoción, los religiosos, debían conformarse con una alimentación simple y austera. Campesinos y artesanos por falta de medios, monjes y frailes por imposición de sus reglas, comían menos y comían en cierto modo peor, aunque acaso para su salud física y moral fuese mejor esta alimentación sencilla, que no dejaba de proporcionar placeres llenos de encanto.

Existían unos preceptos generales que dictaba la Iglesia para todos los fieles, ayuno y abstinencia. Si estas normas alcanzaban a todos los fieles, especial incidencia tenían sobre el clero, que debía desempeñar un papel ejemplificador. Las exigencias de austeridad y mortificación aumentaban cuando se trataba de seguir un camino de perfección espiritual. En la edad moderna las órdenes religiosas seguían representando un modelo de vida alternativo, basado en el ideal de renuncia del cuerpo en favor de los valores del espíritu. Preconizaban pobreza y austeridad y buscaban el dominio del cuerpo a través del ayuno y la abstinencia.

La alimentación de los monasterios y conventos se caracterizaba también por su sentido comunitario. Los religiosos vivían en comunidad, oraban, trabajaban y comían en comunidad. Renunciaban, por tanto, a la privacidad. Toda su vida transcurría en común y juntos comían en el refectorio. Salvo en el caso de los cartujos, que vivían y comían en soledad, los religiosos compartían la mesa. Una mesa igualitaria y también jerárquica, pues la presidencia estaba reservada al abad o al superior. Pero la mesa monástica y conventual no era una mesa de sociabilidad, era una mesa compartida en el acto de comer, el mismo lugar y el mismo tiempo, comían a la vez, los mismos alimentos, pero la comida transcurría en silencio, sin relación personal entre ellos, todos pendientes de la lectura piadosa, que un lector hacía para la comunidad desde el púlpito. El acto de alimentarse transcurría en cierta manera en público, pero con un sentido muy distinto, opuesto, al que tenía lo público en la corte. Retirados del mundo, pero sin el gozo de la privacidad que podían alcanzar algunos privilegiados de la aldea.

Fray Antonio de Guevara también se ocupó del tema de la alimentación y de la mesa en otra de sus obras Oratorio de religiosos y ejercicio de virtuosos, publicada en Valladolid en $1542 .{ }^{19}$ Dedicaba varios capítulos del libro a enfatizar la importancia del

19. Las citas están tomadas de la edición de 1545: Oratorio de religiosos y ejercicio de virtuosos: compuesto por el Ilustre señor don Antonio de Guevara, obispo de Mondoñedo, predicador, cronista, y del consejo del Emperador, y rey nuestro señor. Van en esta obra grandes doctrinas para religiosos, muchos avisos para virtuosos, notables consejos para mundanos, elegantes razones para curiosos, y muy sutiles dichos para hombres sabios. Expónense grandes figuras de la Biblia, decláranse muchas autoridades de la escritura sacra, aléganse dichos de muchos santos, y explícanse ejemplos de los padres antiguos. Es obra en que el autor más tiempo ha gastado, más libros ha revuelto, más sudores ha pasado, más sueño ha perdido y la que él en más alto estilo ha compuesto. El predicador que es amigo de cosas curiosas 
ayuno y la abstinencia en la vida religiosa y a denunciar el pecado de la gula. También trataba de las formas, que se hallaban muy ritualizadas. ${ }^{20}$ Aunque la cortesía era especialmente exigible en la corte, los consejos sobre las buenas maneras en la mesa alcanzaban a los religiosos.

Cuestión principal era el ayuno y la abstinecia, preceptos eclesiásticos que Guevara quería predicar como esenciales para la vida religiosa. En el Capítulo XXIIII, Do se comienza a hablar de las grandes excelencias de la abstinencia: y expónense muchas autoridades de la escritura Guevara alababa el ayuno y la abstinencia:

«Oh si supieses hermanos míos cuán gran don es la de la abstinencia, y cuánto es por todos los santos loada: en verdad os digo, que tuivieseis envidia a los que ayunan y compasión a los que comen: porque la suma verdad del hijo de Dios no hartó a los que en Jerusalén estaban hartos, sino a los que en el desierto estaban hambrientos. La santa abstinencia juntamente con el mundo fue criada, y como tesoro precioso en el paraíso depositada: por manera, que es la virtud primera que al hombre se dio, y aun la primera en que él erró: pues se abstuvo de lo que podía, y comió de lo que no debía. (...) Es bienaventurado el que la abstinencia ama, y mucho más el que la frecuenta.»

En el capítulo XXV, titulado Que entre todas las tentaciones es muy peligrosa la de la gula: y qué es lo que siente San Jerónimo della, Guevara condenaba la gula:

«La tentación de que deseamos ser librados es de la tentación de la gula, del quebrantamiento de la abstinencia, del regalo de la persona, y de la intemperancia ordinaria, y no inmérito la llamó a la tentación de la gula tentación ordinaria: pues no sólo nos tienta cada día, mas aun nos acomete cada hora. Otras tentaciones hay mayores, y otras hay menores, que no la tentación de la gula: mas ninguna nos es tan pesada, ni nos es tan molesta, ni aun sentimos tan importuna como a ella, y por eso hace oración ordinaria contra ella la Iglesia, como contra una pestilencia pública. Mucho es de ponderar, que no pedimos a Dios ser libres de la tentación de la gula, sino que no permita el que caigamos en ella: porque en esta carne mortal no podemos excusar el comer: y después sobre mucho comer o poco comer, está el pecar, o no pecar.»

En el Capítulo XXVI, con el título Que poco aprovecha que ayune el estómago si no se abstiene del pecado: y qué es lo que San Ambrosio siente en esto, comentaba Guevara la verdadera abstinencia, que era más espiritual que material:

predicar y el religioso que es amigo de religiosamente vivir, y el seglar que tiene gana de los bullicios del mundo salir, lean con atención esta obra, que para otro género de gentes no vale cosa. Es obra para que los religiosos la lean en los refictorios: y para que los virtuosos la traigan en las manos. MDXLIIII. Con privilegio imperial. Fue impresa en la muy noble villa de Valladolid, por industria del honrado varón Juan de Villaquirán, impresor de libros, a nueve días del marzo, año de mil y quinientos y cuarenta y cinco. 8 hojas +110 folios.

20. CLARE, Lucien: «Que savoir vivre c'est savoir manger. Les contenances de table prêchées aux moines par l'evêque de Mondoñedo (Antonio de Guevara, Oratorio de Religiosos, 1542), en Duroux, Rose (éd.): Les traités de savoir-vivre en Espagne et au Portugal du Moyen Âge à nos jours, Clermont-Ferrand, Association des Publications de la Faculté des Lettres et Sciences Humanes de Clermont-Ferrand, 1995, pp. 69-91. 
«¿Piensas tú hermano que está la perfección del ayuno en las carnes que dejas, y en las lentejas que comes? El ayuno verdadero es que unjas muy bien la cabeza, y te laves del todo la cara: es a saber, que te aveces a ser virtuoso, y dejes de ser vicioso: porque en la casa del verdadero abstinente, a la hora que ha hambre en el cuerpo, se comienza a hartar el espíritu».

En el Capítulo XXVII, De una carta que escribió San Basilio a Juliano apóstata, a favor de la abstinencia, Guevara ponderaba el voto de pobreza de los religiosos y su expresión en la mesa, que debía ser siempre pobre. En el Capítulo XXVIII, titulado Que el siervo del señor debe huir de los convites mundanos: y que en los más convites del mundo se halló siempre el demonio, recogía diversos ejemplos de las Sagradas Escrituras y de la Antigüedad para apoyar su condena de los convites:

«El fin para que relatamos estos ejemplos es, para avisar y aun aconsejar al siervo del señor, no ose comer fuera de su monasterio, ni que fácilmente acepte los convites del mundo. (...) Entre los hijos del siglo suelen tener costumbre después que han reñido unos con otros irse a comer todos juntos, para tomarse a ser amigos: de manera, que no valen nada las amistades que concertaron los vecinos, sino se confirman después entre los vasos y jarros. Habiendo tú renegado del mundo cuando te hicieron cristiano, y habiendo tú renunciado el mundo cuando entraste religioso: dime yo te ruego, ¿qué otra cosa es ir a comer con los que están en el siglo, sino que quieres tornar a hacer paces con el mundo de nuevo?»

Aconsejaba a los religiosos mantenerse lejos del mundo y de sus tentaciones y para ello le parecía conveniente evitar los convites:

«El monje que presume de buena consciencia, y que se precia de tener vergüenza, no es posible que con los del mundo tenga buena comida: porque si come poco nótanle de hipócrita, y si come mucho infámanle de voraz: y aun cuéntanle las veces que bebe, y nótanle las palabras que habla. Ora nos conviden de veras, ora nos conviden de burla, creedme hermanos y no dudéis, que por más amigos y deudos que sean nuestros, todavía huelgan más de vernos en nuestros monasterios ayunar: que no en sus casas y mesas comer. Por más que tu amigo te ruegue, o que tu pariente te importune, a que vayas a su casa, o que comas a su mesa: tente por dicho, que lo hace más por contigo cumplir, que no porque lo hayas de hacer: pues comúnmente todos los seglares nos quieren más, para que les ayudemos a llorar los pecados que han cometido, que no para que les vamos a comer los manjares que han allegado.»

La conducta más prudente era para los religiosos encerrarse en su convento. Guevara enumeraba las ventajas de comer en el refectorio y las desventajas de comer en el mundo:

«Los que están en el mundo conténtanse con no pecar, mas a los que están en la religión, no les basta no pecar, sino que también deben huir de las ocasiones del pecar: lo cual no hace el monje regalado, y goloso, pues él mismo se convida, aunque no le conviden los del mundo: lo cual parece claro, en que no anda pensando en otra cosa, sino ado podrá haber una buena comida. (...) ¿para qué vas al mundo a ser convidado: pues te pones en aventura, de yendo sobrio y virtuoso, vuelvas malicioso y aun goloso? Si con los que te convidaron quieres hablar cosas de Dios no te oirán, si les hablas cosas vanas escandalízarse han, si les preguntas por nuevas tendránte por curioso, y si no respondes a lo que te preguntan tendránte por necio: de manera, que a la hora que te asientas en alguna mesa 
ajena, pones en examen a tu vida propia. Si de tu natural eres templado y comes poco, estáte en tu monasterio quedo, y si eres voraz y goloso tampoco te aconsejo que aceptes el convite de ninguno: pues una buena comida más es para acrecentar el apetito, que no para amatarte el deseo. Comiendo en tu monasterio, comes en compañía de santos, comes manjares benditos, comes a la hora congrua, comes vianda sana, comes en la regular disciplina, comes so el mérito de la obediencia, y aun comes con lección de la escritura sacra. Si comes en el mundo, has de comer tarde, has de comer de todo, has de comer hablando, has de comer con estrépito, has de estar regocijando, haste de reír si burlaren, has de responder a lo que te preguntaren: y aun has de disimular si te motejaren. Comida tan achacosa para el cuerpo, y tan sospechosa para el ánima, ni se había de aceptar, ni aun en ella oír hablar: pues vale más el pobre ordinario del monasterio, que todos los manjares que nos pueden dar en el mundo.»

Por si, a pesar de todo, los religiosos debían comer fuera de su convento, Fray Antonio de Guevara dedicaba el Capítulo XXIX, titulado De la honestidad y crianza que ha de tener el religioso, cuando comiere fuera del monasterio, a darles buenos consejos sobre el mejor modo de comportarse en sociedad:

«Si movido de caridad, o vencido de humanidad, quieres ir a comer fuera, hazlo por la obediencia, y pide para ello licencia. (...) No te has de contentar, con que el prelado te dé licencia, sino que te dé compañía, y aun compañía que sea honesta y religiosa: porque el monje que osa andar solo pierde el crédito con los suyos, y da mal ejemplo a los otros. (...) El día del convite antes que vayas fuera, oye primero misa, reza hasta el cabo tus horas, y no olvides tus devociones: y no vayas tan temprano que te hagan esperar, ni vayas tan tarde que les hagas desesperar. (...) Llegada ya la hora, bendice ante todas cosas la mesa, y porfía de asentarte en la postrera silla: porque en lo uno mostrarás gravedad: y en lo otro humildad.»

Si la buena crianza era importante en el refectorio del convento mucho mayor debía ser la que mostraran los religiosos cuando comían en casas ajenas. Debían dar buen ejemplo, pero convenía que se adaptaran a los usos y costumbres sociales. El conjunto de consejos resulta muy revelador de lo que se hacía y lo que debía hacerse, comparable a lo recogido en otros tratados de la época como De civilitate morum puerilium de Erasmo de Rotterdam (1530), o Il Galateo de Giovanni della Casa (1558):

«Avísote de una cosa hermano mío, y es que cuanto más fueres religioso recogido, te muestres con todos ser bien criado: pues jamás estorbó la buena crianza, de tener el monje buena consciencia. Asentado a la mesa, no comas hasta que todos coman, ni bebas hasta que todos beban, ni acabes el plato hasta que no quede nada, ni des grandes sorbos en el potaje o cocina, ni pidas a la mesa cosa señalada: porque dado caso que no quebrantes la regla, quebrantas las leyes de buena crianza. Está sobre aviso de no acabar la taza cuando bebieres, ni de derramarlo sobre ti cuando lo gustares: y ten cargo de aguar mucho el vino, y de no te andar con la taza rogando: porque notar al monje de voraz, no sería más de pecado: mas acusarle de ebrio, sería gran sacrilegio. No te limpies las manos a los manteles, no lamas los dedos con la boca, no te suenes las narices con el pañuelo, no te rasques el pescuezo a la mesa, no comas a dos carrillos como mona, no hagas almenas de sopas en la cocina, ni des golpes con los huesos por sacarles la caña: porque en todas estas cosas tomarás poco gusto, y darás allí mal ejemplo. Guárdate de levantar a la mesa pláticas, ni de preguntar allí por nuevas: y si los convidados te convidaren a hablar, no te extrañes de 
les responder: con tal que no seas largo en lo que dijeres, ni porfiado en lo que defendieres: porque el monje porfiado, es primo del loco, y hermano del necio.

Suelen en los convites humanos, después que los estómagos se comienzan a escalentar, y los convidados a se alegrar, hablar en vidas ajenas, y poner mácula en algunas personas: y en tal materia como ésta, guárdate de hablar, ni de tu parecer allí les decir: porque a hacer lo contrario desto, mucho más ponías tú de consciencia, que no ellos de vianda. Si a la mesa donde comes se asentaren dueñas, o comieren doncellas, guárdate de tomar con ellas mucha plática, ni de emplear en ellas la vista: porque allende del escrúpulo que se te puede recrecer, y del buen ejemplo que eres obligado a dar: créeme hermano y no dudes, que no tienes tú tanto cargo de comer, cuanto ellos tienen de pies a cabeza de te mirar. Ten también aviso, en que si el vino que dieren a la mesa fuere malo disimúlalo: y si fuere bueno, no cures de loarlo: pues a la hora que lo has loado y vituperado, das señal de ti, que lo bebiste puro: lo cual es muy mal caso, y muy mal ejemplo: porque entre los mundanos súfrese aguar el vino, más entre los religiosos no se permite sino envinar el agua. No te pongas a los pechos babadero como viejo, no eches el pañizuelo sobre el hombro como cortesano, no despedaces la carne con las manos como despensero, no mordisquees el pan como muchacho, y ni comas muy aprisa como loco: porque según la gravedad que mostrares de fuera a la mesa, te juzgarán que es lo que tienes de dentro en el ánima. Si te pusieren delante muchos manjares, tienes licencia de probarlos, y tienes obligación de loarlos: porque de otra manera, quedaría el que te convidó muy corrido, sino conociese de ti que de la comida ibas contento. Entrar con tres dedos en el plato, tiénese por villanía, no tomar la sal con cuchillo tiénese por grosería, y hablar con el bocado en la boca tiénese por mala crianza: y aun pedir el vino más puro, y el agua más fría, se tiene por muy gran desvergüenza. No te descuides de que en acabando de comer, alimpies las migajas de la mesa, dobles muy bien el pañizuelo, quites la grasa que tiene el cuchillo, sacudas los pechos y mangas del hábito, y recojas tus manos como buen religioso: porque para ser el convite bueno, tú has de loar en ellos la opulenta comida, y ellos en ti la religiosa crianza.

Si por caso estando comiendo, o después que hayas comido, vieres allí algún hombre o mujer que diga donaires, o te provocare a risas, guárdate de dar en la silla de placer grandes palmadas, ni aun con la boca grandes risadas: porque no hay donde ganen honra los que presumen de cuerdos, sino es entre las locuras que hacen los locos. Agua a manos después de comer no la pidas si no te la dan, ni aun la tomes si te la dieren: porque es ley y privilegio de crianza, que solamente se dé al más principal de la comida, y que se asentó a la cabecera de la mesa. Así como no conviene al siervo del señor asentarse a la mesa sin bendecir lo que ha de comer: así no conviene levantarse della sin dar al señor gracias de lo que has comido: pues a él más que a nadie se ha de agradecer todo lo que tenemos, y todo lo que comemos. Está muy sobre aviso a que en pago de los manjares que te dieren los convidados, no te ofrezcas a negociar por ellos algunos negocios mundanos: con los cuales andes después distraído, y tengas necesidad de molestar a su prelado: porque desta manera menos mal te sería la comida que te dieron escotarla, que no con tanto derramamiento pagarla. (...) No te espanten hermano todas estas reglas, ni el avisarte de tantas menudencias: pues eres obligado a guardarlas, no sólo por ser monje, mas aun por ser hombre: porque a todos los del mundo bien les aplace que seas humilde y llano, y mucho les desplace si te ven torpe y mal criado.»

El refectorio era, junto con el coro, la expresión de la comunidad. En el Capítulo XXX, titulado Que el siervo del señor debe siempre ir a comer al refictorio, y huir 
del hospicio, Guevara insistía en la importancia de mantener el espíritu comunitario también en la mesa:

«Todo esto decimos padres míos para avisaros y amonestaros, que pues el señor os llamó a la perfección de la religión y compañía de tan santa congregación, no se extrañe nadie de ir al coro, ni se aparte nadie de dormir en el dormitorio, ni ose comer nadie fuera del refictorio: pues nadie se puede llamar entero religioso, sino el que sigue la vida común del monasterio. (...) Entrando pues en el refictorio asiéntate ado te pusieren, y come de lo que te dieren: y ora sea poco, ora sea mucho, guárdate de mostrar algún descontentamiento dello: pues comes de lo que otros mejores que tú ganaron, y no de lo que tú a la orden trajiste. No tengas respecto a si te asientan más alto o más bajo que a otro monje del monasterio mostrándote agraviado, de que tomases tú el hábito primero que no el otro: porque no puede ser en el mundo igual vanidad, ni aun liviandad, que habiendo tú dejado toda tu reputación y honra por amor de Cristo, la vayas después a buscar en el refictorio.»

Consideraba Guevara, con toda razón, que en la vida religiosa la actitud ante la alimentación transparentaba sus valores más profundos, y que los religiosos debían mantener las buenas maneras en el refectorio, como una expresión más de perfección espiritual. Dedicó el Capítulo XXXIII, titulado De cómo el siervo del señor se ha de haber después que está a la mesa, para que allí conserve la abstinencia y no pierda la crianza, a indicar el comportamiento adecuado de un monje en el refectorio:

«Asentado pues a la mesa, no tomes luego el pañizuelo, ni saques luego los cuchillos, ni asgas luego del pan, ni comiences tampoco a comer, hasta que el lector lea de la lección un poco, y haga señal para comer el prelado: porque el siervo del señor primero ha de recrear el ánima con la santa doctrina que oye, que no apacentar el cuerpo con los manjares que come.»

En el mismo sentido citaba a Hugo de San Víctor, un teólogo medieval. En opinión de Guevara, los religiosos debían guardar recogimiento en el refectorio. Debían escuchar la lectura, guardar silencio y bajar los ojos, para evitar distraerse:

«En la mesa conventual no tienes licencia de hablar palabra, ni de traer por el refictorio derramada la vista: porque según te dice en el libro de la vida solitaria, conviene al novicio claustral tener allí el corazón con el señor ocupado, debe los ojos tener en el suelo, debe los oídos tener en la lección que se lee, y las manos en el manjar que allí come: por manera, que ni por tomar su refeción, no pierda cosa de la honestidad y religión. (...) Si guardas allí bien la vista, ni tendrás envidia a lo que los otros comen, ni aun te pondrás a juzgar de la manera que comen: y si otra cosa haces, no es menos sino que si miras te mirarán, y si te quejas te castigarán.»

Los religiosos debían tener siempre una actitud austera y mortificada ante los alimentos. No habían de ceder a los placeres del gusto, habían de contentarse con considerar la comida como el sustento del cuerpo, pues para ellos debía ser prioritario el alimento del alma. Recogía Guevara una serie de ejemplos de diversas épocas. Citaba a San Bernardo de Claraval, a San Lorenzo Justiniano, a San Agustín de Hipona, a San Anselmo. La actitud de austeridad y mortificación era esencial en los religiosos. Renunciaban a la alimentación como placer, para considerarla sólo como sustento básico: 
«Los del mundo comen para se regalar, mas el siervo del señor no ha de comer sino para se sustentar: porque en las religiones bien ordenadas, permítese que el religioso mantenga el cuerpo: mas no se sufre que satisfaga al apetito. Ni del todo acabes la carne que te ponen, ni del todo agotes el vino que te dan: sino que siempre dejes algo en el vaso, y te sobre algo en el plato: y esto has de hacer, no por satisfacer a tu consciencia, sino por cumplir con la buena crianza. Has de saber hermano mío, que el comer aprisa es de loco, el acabar el plato es de voraz, el lamer los dedos es de goloso, el escurrir el vaso es de borracho, el mirar a todos es de inhonesto, el hablar allí mucho es de atrevido, y el pedir a la mesa algo es de desvergonzado. No pidas a la mesa ninguna cosa, si no fuere solamente pan, y agua: y si te dieren carne y vino, y fruta, inclina al que te lo diere un poco la cabeza: mas si desto no te dieren cosa, has de tener mucha paciencia: porque el verdadero siervo del señor mucho más merece en el sufrimiento que tiene, que no en la abstinencia que hace.»

Fray Antonio de Guevara en sus obras trataba de reunir la rica tradición cultural de Europa, que hunde sus raíces en la cultura judeo-cristiana y en la cultura clásica, y desde una perspectiva humanista, más clerical que cortesana, valoraba los dos mundos entre los que repartió su vida y sus desvelos, el eclesiástico y el cortesano, añorando siempre la sencilla vida de la aldea. La actitud ante la alimentación, las maneras de la mesa se revelan como una buena clave para interpretar la complejidad del autor y de la obra, de aquel mundo y de aquel tiempo, todos sus alcances y todas sus limitaciones, todas sus certidumbres y sus contradicciones, de la corte a la aldea, pasando por monasterios y conventos, desde la intimidad a la sociabilidad, desde lo privado a lo público. 